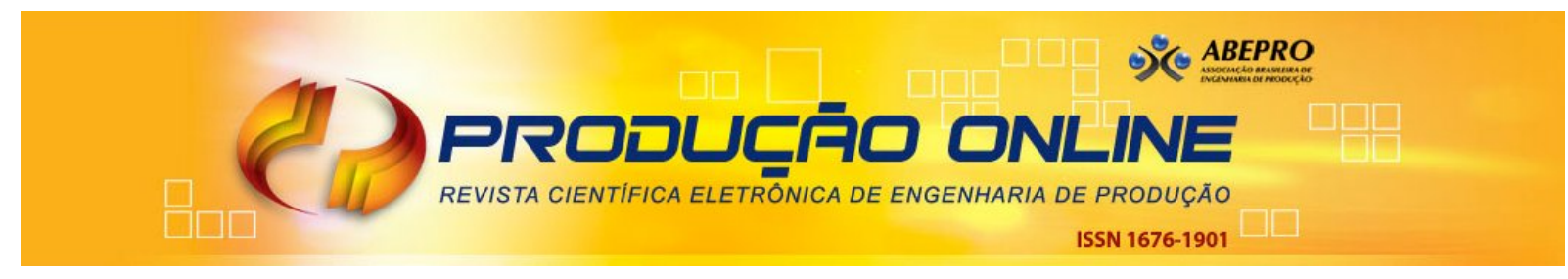

\title{
PROJETO ERGONÔMICO DO TRABALHO E INOVAÇÃO NA DINÂMICA VIRTUAL-ATUAL: UMA CONTRIBUIÇÃO TEÓRICO-CONCEITUAL
}

\section{ERGONOMIC PROJECT OF THE WORK AND INNOVATION IN THE VIRTUAL-ACTUAL DYNAMIC: A THEORETICAL-CONCEPTUAL CONTRIBUTION}

\author{
Gilbert Cardoso Bouyer* E-mail: gilbertcb@uol.com.br \\ *Universidade Federal de Ouro Preto (UFOP), João Monlevade, MG
}

Resumo: O principal objetivo deste artigo é ampliar o atual cenário teórico da área "Ergonomia de Projeto", de acordo com a teoria do conhecimento de criação/inovação, e seus conceitos de virtual e subjetividade no trabalho. Este artigo teórico-conceitual objetiva esclarecer, sob um novo ponto de vista, as relações entre inovação e os atuais esforços em direção a uma teoria científica do conhecimento no Trabalho, com sua complexa estrutura de teorias, hipóteses e disciplinas. Há, neste artigo, uma nova abordagem para compreender o Projeto Ergonômico Contemporâneo, segundo um tipo de abordagem sócio-epistemológica em Engenharia, iniciada por Markus F. Peschl, na Universidade de Viena. Os métodos empregados foram revisão sistemática e adaptação dos conceitos dessa abordagem sócio-epistemológica em engenharia, no atual contexto dos princípios epistemológicos e ontológicos da Ergonomia de Projeto.

Palavras-chave: Ergonomia de Projeto. Conhecimento. Inovação. Atuação.

Abstract: The main purpose of this paper is to amplify the current theoretical scenario of "Ergonomics of Project" area, according to the knowledge creation/innovation theory, and his concepts of virtual and subjectivity in the Work. This theoretical-conceptual article aims to shed new light on the relations between innovation and present-day efforts toward a scientific theory of knowledge in the Work, with its complex structure of theories, hypotheses and disciplines. There is in this paper a new approach to understand the Contemporary Ergonomic Project in a kind of Socio-Epistemological Engineering initiated by Markus F. Peschl in the University of Vienna. The methods employed were the systematic review and adaptation of SocioEpistemological Engineering's concepts in the actual context of epistemological and ontological principles of Ergonomics of Project.

Keywords: Ergonomics of Project. Knowledge. Innovation. Actuation.

\section{INTRODUÇÃO AO PROBLEMA DE PESQUISA TEÓRICA}

\section{A "Abordagem Sócio-Epistemológica em Engenharia" (PESCHL, 2006),} desenvolvida por Markus F. Peschl, na Universidade de Viena, demonstra que o conhecimento reflexivo deve orientar as demais etapas de um conhecimento de criação, inovação e implementação de dispositivos técnicos e tecnológicos em 
Engenharia. Neste texto, aplicar-se-á esta abordagem Sócio-Epistemológica em Engenharia, na denominada "Ergonomia de Projeto" (DANIELLOU, 2004, p. 181). A Ergonomia do Produto se insere na dinâmica de um projeto inovador, no sentido de gerar efeitos ergonomicamente satisfatórios para o usuário ou operador.

Por outro lado, a metodologia da ação ergonômica apresentada por Daniellou e Béguin (2004) compreende-se em métodos alinhados com o trabalho real. Eles foram de fundamental importância para os objetivos deste texto, desde a compreensão do papel da ergonomia no projeto e na inovação até a proposição de meios para iniciar os processos de inovação e projeto inovador. A Ergonomia do produto obedece às mesmas premissas de um projeto inovador calcado nos fundamentos teóricos da ergonomia como um todo. Vejamos.

A Ergonomia do Produto propõe as mesmas premissas da prática científica da Ergonomia (CURIE, 2004). O desenvolvimento de um novo produto não pode abdicar de, desde o projeto, já visualizar as necessidades ergonômicas do usuário.

Projetar o trabalho, e mais restritamente a tarefa (GUÉRIN el al., 2001), envolve o conhecimento e a compreensão do termo que em Ergonomia foi definido por Virtual ou fato virtual (HUBAULT, 2004, p. 123).

O Virtual abriga também o manancial de saber-fazer, macete, "jeitinho", gambiarra (etc.) deveras criativos e potencialmente inovadores. O objetivo deste artigo é demonstrar um ponto de vista um pouco distinto da literatura vigente. É perceber que esta criatividade e este potencial inovadores, que existem clandestinos dentro da empresa, merecem espaços de ação, regulação, diálogo e intercompreensão para que a dinâmica inovadora possa ocorrer. E isso passa pelo que Philipe Lorino denomina de mudanças de mentalidade (LORINO, 2009): partir de uma mentalidade meramente obediente e executora da tarefa para transformação em uma mentalidade criativa e cooperadora.

Este conceito de virtual, da Ergonomia, no presente texto, será mais amplamente detalhado, e teoricamente ampliado, com base nas abordagens, deste mesmo termo, por autores de outros campos do conhecimento. Fato é que a empresa inovadora, que se preocupa também com a inovação do processo de trabalho, está constantemente aos saltos. Numa dinâmica de um binômio ela oscila 
(salta) do atual (real) para o virtual e, novamente, do virtual ao atual (real), estabilizando-se com seu imenso ganho (produto, processo, produção) até o próximo salto, o qual começa em seguida. A cada período de estabilidade, ocorre uma oscilação rumo à criatividade e inventividade (virtual de Hubault (2004, p. 123)). Em palavras mais coloquiais, significa dizer que o virtual é um fluxo de criatividade, inovação, competência no trato com a complexidade e com as situações dinâmicas (HOC, 2004). O modelo fordista é antagônico ao modelo Atual-Virtual.

Alguns autores têm buscado desenvolver uma metodologia de aferição do nível de inovação tecnológica nas organizações (SILVA, HARTMAN, REIS, 2008). Outros já abordaram um sistema setorial de inovação (PEIXOTO, ALMEIDA, VIANA, 2009). Há estudos que partiram para a mensuração de capacidades tecnológicas inovadoras em empresas de economias emergentes, observando os méritos limitações e complementaridades de abordagens existentes (LOURDES, FIGUEIREDO, 2009). A abordagem aqui proposta caminha em harmonia com estes autores e seus estudos pois, de uma forma ou de outra, buscamos modelar e aprofundar nos supostos processos de inovação nas organizações e/ou conglomerados. O "estado-da-arte" no Brasil encontra-se em franco desenvolvimento. Nesse sentido, há trabalhos que pesquisaram também o processo de desenvolvimento de serviços inovadores baseados em modelos de referência como, por exemplo, em Frazzon, Inomata, Oliveira e Forcellini (2015). Mas aqui o nosso modelo de referência é a inventividade, o saber-fazer e o agir subjetivamente implícitos na atividade de trabalho. No real do trabalho encontra-se a matéria-prima da inovação, almejada por tantos autores.

É assim que Cunha, Oliveira e Rozenfeld (2013) chegam mesmo a propor um Planejamento da inovação, com análise e identificação das suas principais fases. Por sua vez, o texto de Espinola, Vilar, Barros e Silva (2009) buscam um indicador do potencial de retorno de investimentos em inovação voltado para regiões do território brasileiro. Alguns indicadores de desempenho do negócio se correlacionam com os esforços de inovação (LAZZARI, BAMPI e MILAN, 2014), oferecendo uma forte possibilidade de mensuração do efeito dos esforços da inovação. 
Para o Projeto do Produto, sob o enfoque da Ergonomia do Produto, emergem soluções de grande qualidade, uma vez que é melhor já conceber o produto, tendo como background o pensamento ergonômico inovador (cuja fonte é o virtual), a ter que corrigir, após a concepção, os problemas que certamente surgirão.

Trata-se, no presente artigo, de uma contribuição teórica, e de uma contribuição conceitual: ampliação teórica e ampliação conceitual. Há, aqui, um objetivo específico de contribuir para as áreas da Engenharia de Produção, envolvidas em:

a) Inovação;

b) Projeto de Processos (em especial, os de Trabalho), Sistemas e Produtos;

c) Gestão do Conhecimento;

d) Ergonomia do Produto e Desenvolvimento;

Demonstrar-se-á a pertinência da dinâmica virtual-atual (abaixo descrita), para a noção de projeto, enquanto um processo dinâmico de inovação, que se pode aplicar nos processos produtivos, industriais e de serviços.

A presente proposta, teórico-conceitual, objetiva ampliar a concepção tradicional de projeto da tarefa e do trabalho (teoricamente e conceitualmente), o que implica em reconhecer que o controle pleno e a antecipação integral dos estados dos processos de produção, hoje pautados pela noção de situações dinâmicas SD (HOC, 2004), não são mais possíveis, como já teria sido no projeto Fordista.

No cenário produtivo contemporâneo, a inovação é um requisito de competitividade; e o projeto inovador não opera mais numa lógica de racionalidade instrumental plena (WHITE, 1995), e sim, como já bem demonstrado na economia e nas ciências da gestão, pelo que alguns autores denominam (com base no pensamento de Simon) de "racionalidade interativa" - "rationalité interactive" (LORINO, 2009, p. 91). A racionalidade interativa permite lidar com ambientes instáveis da produção contemporânea, segundo este autor.

\section{QUESTÕES PROPOSTAS PELO PRESENTE PROBLEMA DE PESQUISA TEÓRICA: UM DEBATE EPISTEMOLÓGICO NA ERGONOMIA DE PROJETO E DO PRODUTO (cf. DANIELLOU, 2004)}


O projeto inovador deve partir para um plano mais global e integrador das variáveis mais operacionais, ao invés de prescrever modos de controle destas variáveis. Para tal, não pode abdicar da compreensão das estratégias operatórias dos trabalhadores (DINIZ; ASSUNÇÃO; LIMA, 2005), situadas na dimensão que François Hubault, em Ergonomia, denomina de Virtual (HUBAULT, 2004, p. 123).

Tradicionalmente, verificava-se, nos projetos rudimentares do trabalho (BRAVERMAN, 1974; FREYSSENET, 1977), uma busca intensa por planificar os mecanismos de controle externo do trabalho (individual e coletivo), numa racionalidade mecanicista e mentalidades precárias (LORINO, 2009). Historicamente, o exemplo de projeto mais sintonizado com esta premissa foi oferecido pelo fordismo (GORZ, 1988; BRAVERMAN, 1974).

O problema aqui investigado, em sua vertente teórica, é dado pela premissa de que, nos dias de hoje, ao invés de tentar antecipar, planificar ou prever todas as situações, e fixar as normas e regras necessárias para com elas lidar, o projeto deve, ao contrário, deixar uma margem, uma brecha, um espaço de inovação, que convide ao emprego das competências (LE BOTERF, 1998; ZARIFIAN, 1999) e da criatividade dos sujeitos (o virtual), com autonomia, sem estabelecer de antemão os modos de agir necessários para enfrentar o caráter dinâmico e complexo das situações reais de trabalho (HOC, 2004). Isso inclui os modos operatórios, as condutas e comportamentos (GUÉRIN et al., 2001). Na concepção aqui discutida, propõe-se que um projeto inovador do trabalho não deve prescrever integralmente os modos operatórios e condutas. A criatividade, a inventividade, a competência, o saber-fazer necessários ao desenvolvimento do produto encontram-se impedidos de emergir quando predomina a lógica do trabalho prescrito, da norma, das punições, da quantidade sem limite.

O desenvolvimento do produto, e a ergonomia do produto, são correntes de teorias e práticas que muito têm a receber da dinâmica do projeto virtual-atual. Um produto inovador é aquele que aterrissou do virtual e se materializou no real. Ele pode novamente entrar no círculo e, assim, sucessivamente, teremos o desenvolvimento contínuo. 
Mostra-se difícil compreender que o projeto inovador deve abdicar de "tudo projetar", para deixar, em aberto, uma lacuna que deve, e pode, ser preenchida pelos sujeitos da ação (LORINO, 2009). Este livre espaço permite, o que em Ergonomia, denomina-se por regulação, margem de manobra e autonomia.

Uma nova visão da geração de conhecimento em engenharia (PESCHL, 2006; PIZO; MENEGON, 2010). O projeto tradicional buscava, geralmente, circunscrever as margens de regulação (GUÉRIN et al., 2001), de adaptação e de autonomia (SCHWARTZ, 1996), ao priorizar as normatizações e fixações objetivas, e detalhadas, dos modos de conduzir a situação dinâmica (HOC, 2004), em cada momento, via padronização de modos operatórios e condutas dos operadores, em contraponto à complexidade do trabalho real (VASCONCELOS et al., 2008). Isso violava as bases de um projeto inovador, no qual o espaço para a cristalização do virtual deve ser mantido em caráter permanente, sem cessar, numa concepção de projeto não mais como algo pronto e acabado, mas sim como algo em constante atualização, em constante recriação pelas potencialidades do virtual, conforme será discutido.

O projeto tradicional da tarefa geralmente se fixava, fundamentalmente, nos aspectos físicos e objetivos dos postos de trabalho, tais como distâncias, dimensões físicas, capacidades, instalações e variáveis técnicas envolvidas. No entanto, seria pertinente um projeto de desenvolvimento das habilidades e competências (LE BOTERF, 1998) dos sujeitos que viriam a operar toda esta objetividade projetada. Além disso, outro elemento do real do trabalho, a variabilidade (ABRAHÃO, 2000), necessita ser absorvido no escopo do projeto, desde o seu início, de modo a reduzir as cargas de trabalho dos operadores (WISNER, 2004, 1994, 1987), até sua implementação prática e funcionamento. Mas não há como lidar com a variabilidade sem espaço para autonomia, sem regulações e margens de manobra. Isso é o que nos ensina o fato virtual: pura mudança, puro desenvolvimento, pura inovação e espaço para regulação, autonomia e inventividade.

Observa-se que o projeto tradicional não envolvia uma dimensão subjetiva virtual - em seu escopo, ou seja, não tratava da história (passado) dos agentes, nem de suas competências, habilidades e saberes. Essa é a parte subjetiva do trabalho. 
Tampouco de seu saber fazer tácito e de suas potencialidades tais como criatividade, inventividade e iniciativa (ZARIFIAN, 1999) - ou seja, elementos do real do trabalho que efetivamente, como já demonstrado historicamente, asseguram o funcionamento dos processos de produção, das instalações e dos equipamentos via atividade de trabalho (DANIELLOU, 2004; DANIELLOU \& BÉGUIN, 2004; LEPLAT, 2008). Mas o fenômeno de praticar a inteligência e a criatividade não pode ser inteiramente deixado a cargo dos operadores. Há que se adquirir uma cultura que favoreça a criatividade, quer nas alterações do processo, quer no desenvolvimento de novos produtos ou ainda no desenvolvimento e melhoria de produtos existentes. O mecanismo de emergência dessa cultura é a cooperação.

No entanto, projetavam-se estes últimos (instalações e equipamentos), em seu caráter objetivo e prático, sem que, no escopo do projeto tradicional, verificassese um detalhamento sobre o viés subjetivo (LINHART, 2010) que mantém a produção, as instalações e os equipamentos, em funcionamento, na produção: o "fato virtual" ou virtual (HUBAULT, 2004, P. 123); o trabalho real (PIZO; MENEGON, 2010) e a atividade de trabalho em seus aspectos subjetivos (ABRAHÃO; TORRES, 2004; DANIELLOU, 2004; LEPLAT, 2008).

Ontologicamente, como será discutido neste texto, sabe-se que o trabalho não é apenas um fato objetivo, como os demais do mundo natural, mas sim aquele "fato virtual", assim denominado e descrito por Hubault (2004, p. 123). O trabalho é um fato, também, subjetivo (CLOT, 2004; BATIONO-TILLON; FOLCHER; RABARDEL, 2010). Trabalhar é colocar a subjetividade em ação (HUBAULT, 2004; LINHART, 2010; SCHWARTZ, 1996). Trabalho e subjetividade são indissociáveis, numa caracterização ontologicamente subjetiva do trabalho, e da consequente identidade do sujeito do trabalho (PASTRÉ, 2005).

Entretanto, verifica-se, na prática, que o projeto tradicional da tarefa vinha a se chocar com esta constatação ontológica apontada por Pastré (2005). Se o trabalho é também subjetivo (virtual), e não um fato integralmente objetivo, tudo que o processo tradicional de projeto da tarefa historicamente fazia (FREYSSENET, 1977) era projetar os aspectos objetivos, físicos e quantitativos ligados à noção de tarefa propriamente dita, e do posto de trabalho a ela correspondente (GUÉRIN et 
al., 2001). Não se "projetava a subjetividade" em ação - o virtual (HUBAULT, 2004, p. 123). Não se verificou, na história dos processos de trabalho, uma tradição, em projeto, de envolver, em seu escopo, a realidade ontológica da atividade: a subjetividade, a interioridade, o tempo (não cronológico) do passado-memória (BERGSON, 1999) - o virtual. Ou ainda, a variabilidade (ABRAHÃO, 2000); e também o que Yves Schwartz chama de ingrediente tácito da competência (SCHWARTZ, 1996). São também estes elementos do passado-memória dos operadores mais antigos que têm a força e o poder de revigorar as atividades de projeto e inovação. Essa realidade parece óbvia, mas não é. Em muitas situações por nós investigadas, em situações reais de ação, os operadores "mais velhos" são deixados em segundo plano em relação aos jovens que adentram a empresa com toda energia da formação acadêmica.

A epistemologia da Ergonomia já registrou, em diferentes campos do conhecimento interdisciplinar sobre o trabalho (DANIELLOU, 2004) que, ontologicamente, trabalhar é colocar a interioridade, o tempo não-cronológico, o virtual enquanto duração "durée" (PASTRÉ, 2005; BERGSON, 1999, 2004), e a subjetividade - categorias subjetivas - em serviço, ou a serviço da produção objetiva. Por exemplo, um saber-fazer específico, que permite solucionar um problema com agilidade e em tempo curto, é uma categoria subjetiva que foi desenvolvida ao longo dos anos de vivência do processo de trabalho. Trabalhar é colocar a si mesmo (SCHWARTZ, 1996) a serviço dos objetivos prescritos no projeto tradicional da tarefa - é "usar de si por si mesmo" nas precisas palavras de Yves Schwartz (1996). Entretanto, o projeto tradicional da tarefa (como o de Ford) não incluía, em seu escopo, essa subjetividade produtiva (LINHART, 2010). Tradicionalmente, a realidade projetiva perdia contato com a realidade ontológica do mundo do trabalho (CURIE, 2004), no projeto tradicional.

Como então os projetos funcionavam, no cerne desta falha ontológica? Eles funcionam, quando postos em prática, justamente em função das componentes subjetivas da competência (SCHWARTZ, 1996), e da própria competência (ZARIFIAN, 1999; LE BOTERF, 1998). São esses elementos mais interiores da atividade cognitiva que faziam aqueles sistemas e processos de produção 
funcionarem a contento; e não apenas o que fora descrito objetivamente no projeto. O constante recriar, reinventar, regular e adaptar, mobilizados tacitamente/subjetivamente pelos trabalhadores, é o que supria as carências do projeto tradicional, ainda que esta dimensão virtual (HUBAULT, 2004, p. 123) não seja plenamente visível, e tampouco reconhecida na racionalidade projetiva (LORINO, 2009). A racionalidade da inovação é distinta da racionalidade instrumental, em especial na diferenciação temporal. Na inovação, a lógica é movida pela criatividade (que demanda espaço e tempo para a criação), ao passo que a racionalidade instrumental é aquela de Taylor-Ford, ou seja, a do controle baseado no tempo cronológico.

\section{UMA CONTRIBUIÇÃO TEÓRICO-CONCEITUAL AO PROJETO TRADICIONAL DA TAREFA}

As ideias e a criatividade necessitam de espaço para emergirem no sistema de produção (industrial e de serviços). A questão pode parecer simples ou óbvia, mas a vertente tradicional de projeto não criava espaços para a contribuição criativa dos agentes da produção (LORINO, 2009; ZARIFIAN, 1999). Como consequência, soluções, inovações e contribuições criativas, para o trabalho e a produção, e para o produto, eram perdidas, ante a ausência de espaço para surgir - nem na fase de criação e desenvolvimento do projeto, e nem ao longo de sua implementação e funcionamento prático.

Ou seja, a parte do virtual (HUBAULT, 2004, p. 123; BERGSON, 1999, 2004, 2007), discutida aqui, não se cristalizava na forma de soluções e sugestões, de grande relevância para o desempenho do projeto, e para a eficiência dos sistemas de produção e trabalho. Isso se tornava mais grave, por uma visão equivocada do conhecimento nas organizações e na engenharia (PESCHL, 2006). Confundia-se conhecimento formal, teórico e epistemológico (Figura 1, plano EpF) com saber prático e tácito (Plano P da Figura 1). Em estudos empíricos realizados pelo mesmo programa de pesquisa que deu origem ao presente artigo, verificou-se que, na maioria das vezes, os operários que não possuíam uma formação acadêmica, eram considerados menos aptos a participar do projeto. O espaço de inovação/projeto, 
naqueles casos estudados, era amplamente preenchido pelos engenheiros, tecnólogos e, mais recentemente, pelos especialistas da computação.

Esse grave equívoco somente pôde ser detectado, nos estudos empíricos, pela compreensão plena da noção de saber-fazer tácito, de inteligência astuciosa (da prática) ou de saber incorporado da competência dos operadores (SCHWARTZ, 1996). A prata da casa é um manancial de saberes e competências cuja negligência dilapida o potencial inovador. Observou-se, ali, que todos estes elementos pertenciam ao real do trabalho (CURIE, 2004) e ao seu virtual (HUBAULT, 2004). Todos eram elementos de uma imagem virtual (Figura 4 discutida a seguir). Embora não possuíssem diploma de Universidade, havia, nos grupos estudados, operários dotados de um saber fazer, e de um tipo específico de conhecimento tácito, relevante ao projeto, mas que diferia do saber dos especialistas, não em qualidade, mas em natureza. O saber-fazer é um saber prático adquirido ao longo dos anos em ação num certo processo. Ele é um saber tácito porque não pode ser transmitido completamente de forma verbal.

Essa necessária criação de espaço para o virtual se projetar/atualizar, no presente do projeto, requer algumas condições. Inicialmente, a criação de espaço físico - no sentido comum do termo. Paralelamente, o desenvolvimento de novas formas de controle que não prejudiquem a espontaneidade dos trabalhadores e sua potencial capacidade de contribuição na parte inovadora do projeto.

Ou seja, é necessário um espaço físico para a manifestação das ideias como uma sala ou escritório, específicos para tal. Este espaço não pode descartar o espaço operacional da produção - o comumente chamado "chão-de-fábrica" - no qual emergem sugestões e soluções, no curso da ação em "tempo real" (HOC, 2004; THEUREAU, 2004; AMALBERTI, 1996). E um espaço virtual, para expressão objetiva da criatividade e da inovação, as quais têm sua gênese no rompimento de aspectos inflexíveis de controle sobre os sujeitos (BRAVERMAN, 1974) - algo do tipo autonomia intelectual para os níveis hierárquicos menos elevados na escala da organização. Em outras palavras, uma espécie de ruptura com a relação clássica entre hierarquia e poder de participação criativa. 
Ainda que no topo mais elementar da estrutura hierárquica, deve haver espaço (virtual e físico) para que sugestões e soluções sejam expressas em diferentes formas de linguagem e expressão. Isso se mostra difícil, porque requer mudança de mentalidade (LORINO, 2009). E, principalmente, a criação de mecanismos reais e eficazes de participação deontológica e comunicacional, deliberativa (WHITE, 1995), nos processos criativos e de inovação (projeto), via incitação da atualização do virtual - de "fato virtual" ao "fato atual" (HUBAULT, 2004, p. 123) - na atividade projetiva inovadora.

Já exaustivamente demonstrado na Ergonomia, tem-se que o trabalhar não é um fato objetivo, na mesma dimensão ontológica dos demais objetos físicos do ambiente de trabalho. Trabalhar é objetivar (projetar/materializar), no presente, o virtual - a subjetividade atrelada às competências tácitas (SCHWARTZ, 1996). Trabalhar aproxima-se, então, do agir e não apenas do fazer (HUBAULT, 2004). Consiste em mobilizar o que se possui de mais subjetivo, ou seja, da interioridade cognitiva e psíquica (haja vista as cargas cognitiva e psíquica da atividade de trabalho), como um saber-fazer, um macete, um "jeitinho" (termo brasileiro conhecido por outras palavras em diferentes idiomas), uma gambiarra e um poder de agir e uma capacidade de agir (PASTRÈ, 2005) a favor de um objetivo específico da produção. Trabalhar é, portanto, colocar a subjetividade - o virtual - em ação (SCHWARTZ, 1996; HUBAULT, 2004).

No entanto, a contribuição criativa, necessária à inovação, não é dotada de poder para romper com a rigidez hierárquica que geralmente a bloqueia (Figura 3 a seguir). O virtual criativo requer que sua finalidade harmonize-se (entre em ressonância) com os objetivos do processo de produção: competitividade, produtividade, eficiência, eficácia e inovação. Mas o sujeito não pode definir onde e como - com qual finalidade - contribuir na construção da inovação e da criação do novo. Isso compete aos gestores do processo, os quais devem criar os espaços (anteriormente discutidos como espaço físico e virtual) - em todos os níveis hierárquicos - para que, assim, possa emergir a solução criativa, a sugestão inovadora, a própria inovação. 
Faz-se necessário abrir espaços de comunicação deliberativa (WHITE, 1995), na teia complexa e intrincada da hierarquia, de modo a fazer emergir criatividade, inovação, inventividade - fatos do virtual (HUBAULT, 2004, p. 123) que necessitam se atualizar no real e no presente como fatos atuais.

\section{A DINÂMICA DO CONHECIMENTO DE INOVAÇÃO EM PROJETO NO CIRCUITO VIRTUAL-ATUAL}

A reflexão sobre a técnica, como uma forma de conhecimento reflexivo, é o ápice do processo criativo necessário à inovação, similar ao que já foi demonstrado, por Markus Peschl, no campo daquilo que ele denomina de "engenharia sócioepistemológica" (PESCHL, 2006). Schön (2000) utiliza o termo "reflexão-na-ação" para designar processos de aprendizagem e desenvolvimento que ocorrem no interior da ação, vindo a ser o conhecimento algo que se inicia na ação e atinge níveis avançados de reflexão na própria ação, sendo, portanto, indissociáveis ação e reflexão.

É preciso ir além de um conhecimento meramente operacional, quando se trata de compreender, criar e finalmente Inovar. A inovação não pode jamais prescindir de um conhecimento mais abrangente e integrador, que busque avaliar as implicações dos conhecimentos mais objetivos e aplicados, diretamente ligados à técnica, no plano material da prática (Plano $\mathrm{P}$ da Figura 1). A literatura do conhecimento organizacional denomina este conhecimento de reflexivo (PESCHL, 2006) e construtivista (SCHON, 2000). O termo reflexão-na-ação, anteriormente descrito, filia-se ao construtivismo - o conhecimento é uma construção pela ação.

Embora o produto da inovação vá se atualizar em dispositivos ou processos materialmente inseridos num funcionamento prático, no processo de produção, o conhecimento que permite compreender o próprio processo criativo envolvido na inovação - incluindo os seus componentes do desenvolvimento cognitivo (ARENDT, 2000) - situa-se numa dimensão mais elevada dos "processos de conhecer", conforme esta denominação, e sua pertinente hierarquização, elaboradas por Peschl (2006). A aplicação da ciência (ciência aplicada) - e a história da ciência assim o 
demonstram (CHALMERS, 1999) - jamais se distanciou de processos de compreensão e reflexão instalados nas esferas mais altas do conhecimento aí em pauta (PESCHL, 2006). Criar e inovar não têm como se dar longe de um entendimento dos processos de criação e inovação, em suas estruturas epistemológicas (Plano EpF da Figura 1); e estruturas de compreensão conceitual e teórica (Plano TC da Figura 1), da sua realidade de criação, desenvolvimento e aplicabilidade no contexto social da produção.

Pela Figura 1, pode-se visualizar, sinteticamente, esta abordagem teórica. O universo epistemológico e filosófico do conhecimento (EpF), e da pesquisa científica, está na posição de orientar as demais fases do processo de inovação e implementação (ponto I, na base da ilustração) de dispositivos aplicados, e/ou técnicas/procedimentos, no plano $\mathrm{P}$ do real do trabalho.

Figura 1 - Do universo epistemológico e filosófico (EpF) à aplicação prática do conhecimento no plano P do Real do Trabalho

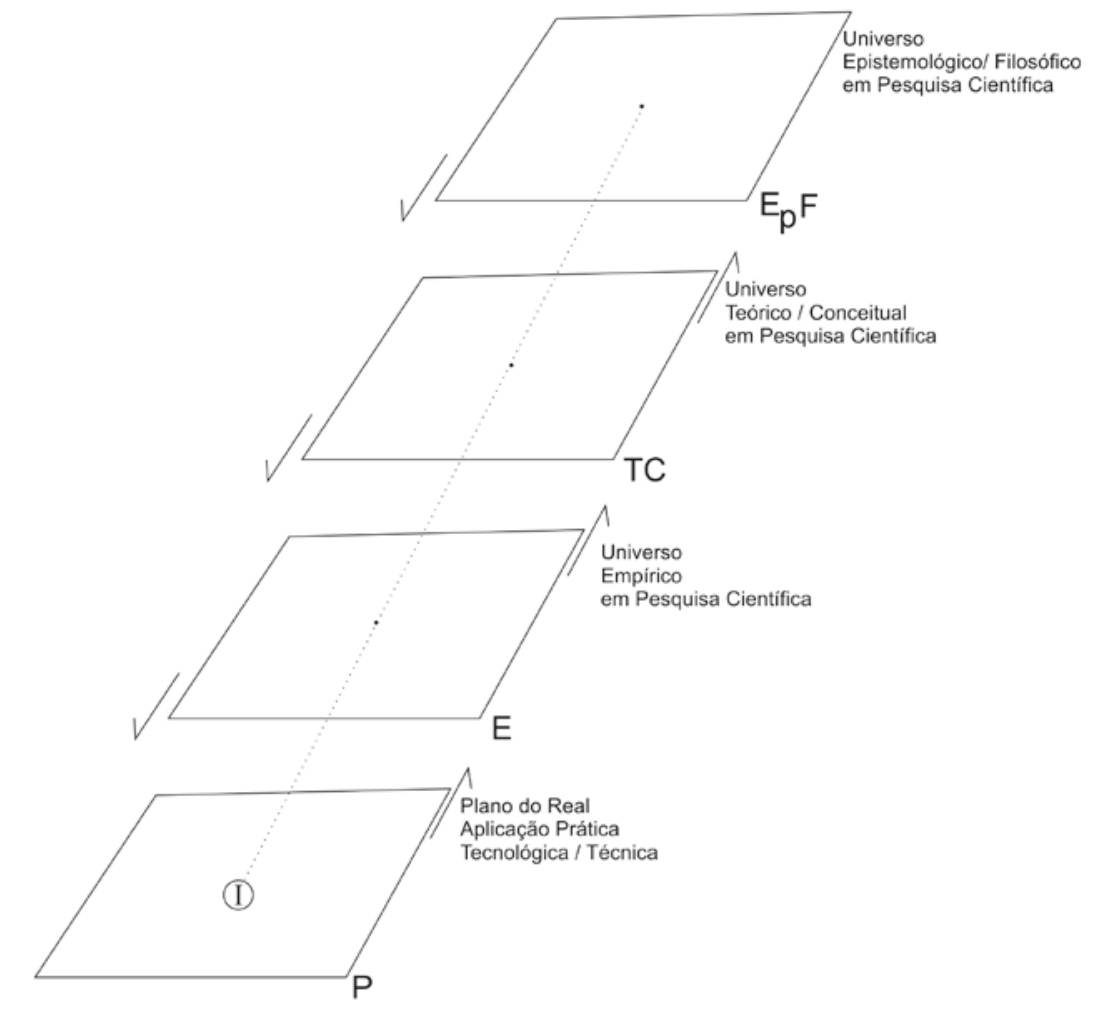

Fonte: Adaptado de Peschl(2006) 
O universo teórico e conceitual (TC), abaixo de EpF, constitui um verdadeiro corpo da empreitada de inovação e desenvolvimento tecnológico, haja vista que os conceitos são verdadeiros fótons de descrição e elucidação do conhecimento (VYGOTSKY, 1996), ainda mais em se tratando de conhecimentos de ponta, construídos ao longo de uma história de pensamento e desenvolvimento de um dado campo científico específico. Sem os conceitos e teorias, o conhecimento esvazia-se de conteúdo, tornando-se uma mera reprodução de formas de replicação, ou técnicas, desprendidas da tradição de sua própria gênese.

Embora em muitas perspectivas positivistas e objetivistas, o universo empírico (Plano E, na Figura 1) em pesquisa científica - localizado abaixo do Plano TC adquira um status supervalorizado pelas comunidades científicas em todo mundo (como, por exemplo, as medições e estatísticas), na realidade, o empírico não possui, por si só, sentido algum. O sentido do universo empírico (Plano E, na Figura 1), e sua própria razão de existir, somente adquirem primazia ontológica sob a égide dos dois universos, epistemológico e conceitual (PESCHL, 2006), que the são superiores: EpF e TC.

A aplicação prática/tecnológica, e o mundo das técnicas, (Plano P), situam-se na base da Figura 1, não por uma questão de inferioridade hierárquica mas, pelo contrário, porque a base concreta, material, de validação e verificação, de todos os demais universos ontológicos de conhecimento, é a prática. No entanto, embora situada na objetividade do mundo material, e do Real (do trabalho), ela (a prática...) se orienta pelos conceitos, teorias e conhecimento reflexivo-epistemológico que a envolvem (PESCHL, 2006).

Observa-se, pela Figura 1, que há setas em dois sentidos: descendente, do universo EpF até o plano do real $\mathrm{P}$ e; em sentido inverso, ascendente, do plano prático e aplicado $\mathrm{P}$ até o nível de reflexão e compreensão situados no Plano superior EpF. Isso traduz a abordagem construtivista do conhecimento (SCHON, 2000; PESCHL, 2006). Ou seja, significa que não se trata de um processo estático de conhecimento, mas sim dinâmico, no qual a prática é constantemente orientada pela reflexão e pelos conceitos e teorias; enquanto que estas são continuamente 
colocadas sob avaliação e verificação pela práxis da tecnologia, que se atualiza, a todo momento, na prática do plano do real (Plano P da Figura 1).

Uma teoria, um conceito, podem ser reelaborados sob a guia dos resultados práticos da aplicação/verificação empírica, e pela implementação (ponto I da Figura 1, no Plano P), ou não implementação, quando de sua não-validação (das teorias e conceitos) pelos artefatos, dispositivos, técnicas e procedimentos objetivos situados no plano Real, prático, ou Plano P (Figura 1), dos processos de produção contemporâneos. Portanto, a teoria está sob o julgamento da prática (Plano P da Figura 1), para usar aqui alguns termos do senso comum, por fins de clareza. Por outro lado, a prática está sob a guia da reflexão (PESCHL, 2006; SCHON, 2000) e compreensão, teóricas (Plano EpF da Figura 1).

Nos processos mais elevados de reflexão e compreensão, sobre a ação (PESCHL, 2006; SCHON, 2000), representados pela base AB do cone invertido da Figura 2 abaixo, tem-se a presença do virtual (HUBAULT, 2004, p. 123) descrito anteriormente. Trata-se da parte subjetiva do processo de criação/inovação. Na ponta do cone invertido (Ponto S, na parte inferior da Figura 2), situada no plano prático, atual, P (real do trabalho), tem-se que este ponto S é constituído por pura ação e percepção, no espaço concreto, material, dos processos de produção. O ponto S consiste em ação, em materialidade, em projeção-atualização, no plano do real $P$, daquilo que era puramente virtual (reta $A B$ da base do cone invertido, no alto da figura). Em síntese, a dinâmica de $A B$ até $S$, e de $S$ até $A B$, da Figura 2, descreve o circuito virtual-atual da dinâmica de inovação em projeto.

O ponto S representa o desfecho do processo construtivista, material e concreto de reflexão na ação (SCHÖN, 2000), em que, no momento presente, no próprio ato material de aplicação do dispositivo ou da técnica, cognitivamente, o agente da prática "dialoga com a situação", por meio da práxis, obtendo respostas que remetem o processo a seus estágios mais virtuais ou abstratos de criação (Ponto $C$ da reta $A B$, no topo da Figura 2). Novamente, apresenta-se uma temporalidade dinâmica da cognição ou "transparency" (VARELA, 1999, p. 298), em que a dinâmica criativa não se prende nem no ponto extremo $S$ (parta inferior da Figura 2), nem no ponto virtual $C$ da reta $A B$ (parte superior da Figura 2). $O$ 
pensamento criativo envolvido na inovação (PESCHL, 2006) oscila continuamente, de modo dinâmico, entre os extremos S e C, passando pelos níveis intermediários de compreensão e reflexão (seções do tipo A'B'; A"B" ... da Figura 2). Esses movimentos não podem ser paralisados, sob pena da perda da inventividade, da criatividade e etc.

Figura 2 - A abordagem construtivista do conhecimento de inovação (reflexão-ação) no circuito dinâmico entre virtual $(A B)$ e atual $(S)$

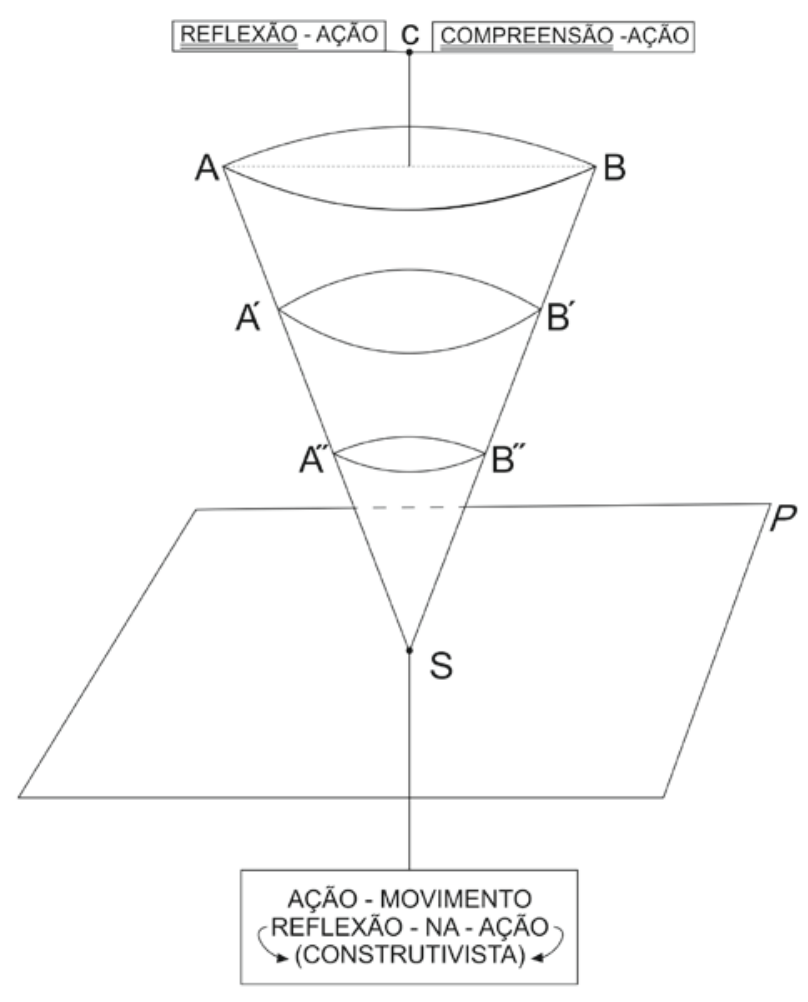

$A$ base $A B$ do cone invertido, localizada no alto da Figura 2, representa, também, a memória, o passado, a lembrança - o Virtual (BERGSON, 1999; DELEUZE, 1966). Uma base repleta de saberes, conhecimentos e lembranças que são substâncias relevantes para o processo criativo de inovação. Parte deste virtual bergsoniano foi aplicado, na Ergonomia, por Hubault (2004, p. 123). Este passado/memória $A B$ projeta-se (atualiza-se), ininterruptamente, em caráter contínuo, no tempo presente (o atual), representado pelo ponto $S$ (vértice do cone invertido da Figura 2). 
Resumidamente, o ponto $S$ é o atual: saber corporificado (SCHWARTZ, 1996), inteligência da prática e percepção. Difícil compreendê-lo como um ponto, visto que ele já abarca (como ponto) todo o passado deste presente - passado como imagem virtual, que entra em circuito com a imagem atual (DELEUZE, 2007, p. 101). As seções do cone, A'B'; A"B", são circuitos virtuais, cada uma delas englobando todo o passado tal como ele se conserva em si. São estágios de criação, de pensamento inventivo, que fluem no sentido de uma aplicação prática, ou materialização, no ponto $S$ (atual). E fluem no sentido do virtual $A B$, como reflexão e crítica quanto às aplicações práticas em engenharia (PESCHL, 2006).

Este circuito dinâmico virtual-atual não comporta a reprodução do conhecimento, e sim, pauta-se pela sua inovação. Sempre que o virtual muda de natureza, ao se atualizar no presente (DELEUZE, 1966), ocorre a geração de algo distinto e novo. O passado, ao contrário do que faz pensar o senso comum, é, em Bergson $(1999,2007)$, um reservatório de inovação a desembocar, a cada instante, no momento presente, mudando sua natureza de virtual para atual e, assim, gerando a inovação e a criação do novo, atualizados em tecnologias e dispositivos aplicados (ponto S).

\section{PROJETO ERGONÔMICO DO TRABALHO E INOVAÇÃO: A DINÂMICA ENTRE O FATO VIRTUAL E O FATO ATUAI (HUBAULT, 2004, p. 123)}

Projetar o trabalho envolve uma contradição ontológica. Se por um lado, é necessário um pensamento prévio, uma planificação sobre o que será feito, antes de colocar o trabalho em prática, numa busca de obter o máximo de controle possível (BRAVERMAN, 1974); por outro lado, há elementos do trabalho que jamais podem ser premeditados e antevistos no projeto; e que não podem ser controlados de forma plena. Em outras palavras, projetar é fixar, no tempo e no espaço, uma visão antecipada do que será o trabalho (LORINO, 2009). Historicamente, foi uma busca incessante por maximizar o controle, segundo uma visão do objetivismo no controle do trabalho estilizada por Ford (BRAVERMAN, 1974; FREYSSENET, 1977). 
Paradoxalmente, há elementos do trabalho que não podem ser previstos e fixados, de antemão, no tempo e no espaço - e que não permitem um controle total. Logo, rompem com a noção de Projeto, tradicionalmente associada à previsão, controle e fixação, como na noção de co-presença, de Zarifian (1999).

Projetar o trabalho, numa nova concepção teórico-conceitual, é lidar com esta contradição. Prever formas de controle para algo que permite apenas controle parcial, como no caso das situações dinâmicas de produção (HOC, 2004), requer uma nova concepção da própria noção de controle e supervisão de processo. Estamos no campo de uma racionalidade limitada (LORINO, 2009), na qual não é possível um controle pleno das situações (dinâmicas) e, portanto, não se pode operar com os mesmos dispositivos de poder e controle de Taylor-Ford. Solicita, portanto, a compreensão dos denominados compromissos cognitivos de gestão dos riscos e situações dinâmicas (AMALBERTI, 1996, 2004; HOC, 2004).

Tem-se a hipótese, então, que o projeto do trabalho real não se adapta ao sentido tradicional do termo "projeto", visto que nele se abriga o real do trabalho e sua virtualidade (HUBAULT, 2004): aquilo que escapa ante as tentativas de simbolização; o que não se apresenta facilmente ao domínio da técnica; do saber científico e tecnológico; das regras e procedimentos. O que se pode projetar (no campo do possível) é a tarefa.

Há um paradoxo no projeto do trabalho. A tarefa (GUÉRIN et al., 2001) enquadra-se no projeto tradicional, mas a tarefa não é o trabalho por inteiro. Como projetar o trabalho real, em seu aspecto virtual, é uma questão já levantada na Ergonomia (HUBAULT, 2004; DANIELLOU, 2004). Ainda que a atividade de projetar envolva o exercício da técnica e da ciência, o imprescindível à estrutura do projeto se mostra reticente ante as tentativas de formulação e prescrição:

1) A variabilidade das situações de produção; dos indivíduos e dos sistemas sócio-técnicos (ABRAHÃO, 2000; WISNER, 1987, 1994);

2) A diversidade dos modos operatórios; e o fato de ser o modo operatório uma resultante complexa, de uma miríade de variáveis inter-relacionadas (GUÉRIN et al., 2001; WISNER, 1987, 1994), quais sejam (cf. GUÉRIN et al, 2001):

i) Os objetivos estipulados; 
ii) Os resultados a alcançar;

iii) Os recursos, meios e condições de trabalho disponíveis (ou não);

iv) O estado interno do organismo (fisiológico e psíquico);

v) As cargas de trabalho e suas componentes (física, psíquica e cognitiva);

vi) Os graus de liberdade para as adaptações necessárias e as margens de manobra (mais amplas ou menos amplas): regulações.

3) A regulação das cargas de trabalho e dos modos operatórios (GUÉRIN et al., 2001), diante das variabilidades e oscilações do sistema dinâmico de produção e suas situações dinâmicas (HOC, 2004).

Isso demonstra que projetar o trabalho não significa projetar o posto de trabalho, em suas dimensões físicas apenas. Implica em dimensionar, principalmente, o que não pode ser inteiramente previsto, antecipado e controlado: a variabilidade; a diversidade dos modos operatórios; a regulação e a adaptação frente às situações dinâmicas de produção (HOC, 2004), as quais demandam complexos compromissos cognitivos por parte dos operadores (AMALBERTI, 1996, 2004). Não mais é possível o controle como na racionalidade restrita e limitada dos modelos engessados e estáticos dos processos de trabalho. Há que se atender, no projeto integrado e inovador, os fundamentos da ergonomia anteriormente apontados; inclusive os da Ergonomia do Produto. Menos controle, mais espaço para a cooperação, a criatividade, a inovação. É deixar jorrar na produção o fluxo contínuo do virtual para o real.

Ou seja, o trabalho real é essencialmente subjetivo (SCHWARTZ, 1996; LINHART, 2010; HUBAULT, 2004). Aquilo que se observa externamente, como gestos e operações, não corresponde ao trabalho em si. O trabalho abriga a subjetividade, responsável por criar soluções e recriar aquilo que foi prescrito pela tarefa. Trabalhar é preencher a lacuna inesgotável entre trabalho prescrito e trabalho real, por meio da engenhosidade, do zelo e da inteligência da prática (SCHWARTZ, 1996). Estes ingredientes subjetivos não podem ser prescritos nem projetados objetivamente, em sua totalidade. Eles integram a subjetividade, parcela essencial da atividade, que engloba também os compromissos cognitivos (AMALBERTI, 1996, 
2004), as regulações e as estratégias operatórias (DINIZ; ASSUNÇÃO; LIMA, 2005) para lidar com a variabilidade das situações de produção. O virtual.

O projeto geralmente busca antecipar - prever - situações futuras, para conceber dispositivos e técnicas apropriados a elas. Ele objetiva então racionalizar a dinâmica das situações reais, de modo a, antecipadamente, determinar mecanismos ótimos de controle, modos adequados de funcionamento dos dispositivos, em situações para as quais se destinam; e as próprias características dos dispositivos tecnológicos necessários a um dado sistema (DANIELLOU, 2004). No entanto, a racionalidade do projeto do trabalho ("rationalité interactive") difere radicalmente da racionalidade do projeto de sistemas essencialmente técnicos (LORINO, 2009). Em contraponto à busca por um controle objetivo, preciso e pleno das situações e dos sistemas, que anteveja todas as possibilidades de articulação entre as variáveis e esgote todas as regras de controle destas, o projeto da tarefa acaba por reconhecer a existência de uma "rationalité interactive" (racionalidade interativa) (idem, p. 91).

Ou seja, o Projeto Ergonômico do Trabalho (para além do projeto da tarefa) requer uma atividade distinta do projeto tradicional da tarefa, no sentido de deixar uma margem de manobra mais ampla aos sujeitos dos sistemas sócio-técnicos envolvidos; de abdicar da busca por uma racionalidade que antecipe e controle todas as situações previstas; e por ceder uma certa fluidez, uma espécie de zona de indeterminação (LORINO, 2009), no cerne do projeto em si, a qual somente será completada pela atividade concreta, e contextualizada, dos sujeitos em situação de trabalho - no real do trabalho.

Isso significa que "projetar" requer deixar espaço para o fluxo dinâmico da inventividade, da criatividade, anteriormente demonstrado na dinâmica do cone invertido da Figura 2. E requer o teste de hipóteses, pela ação, no plano da prática (Plano P da Figura 1), das teorias e premissas situadas no Plano EpF (Figura 1) - 0 modelo da "reflexão-na-ação" (SCHON, 2000). Pode demandar, ainda, a remissão de $\mathrm{P}$ ao nível EpF, quando a ação demonstrar a necessidade de atualização da teoria e/ou das premissas vigentes (sentido ascendente da Figura 1, indo do Plano P ao Plano EpF), como descrito por Peschl (2006), em sua noção de conhecimento 
reflexivo, necessário ao conhecimento essencialmente técnico e operacional aplicado nos dispositivos tecnológicos, e em seu manuseio.

O circuito atual-virtual (DELEUZE, 2007, p. 99-104; HUBAULT, 2004, p. 121123), necessário à atualização/inovação, demanda margens amplas de manobra. Por isso, projetar o trabalho é também deixar uma lacuna de projeto como forma de permitir a mobilização, o exercício da iniciativa, da criatividade, da engenhosidade, do zelo e da inteligência da prática - ingredientes da subjetividade - imprescindíveis ao funcionamento ótimo de um sistema sócio-técnico. Como projetar essa zona de indeterminação é uma questão para a atividade projetiva contemporânea.

Verifica-se, na história dos sistemas de produção e trabalho (GORZ, 1988; FREYSSENET, 1977), que o projeto era concebido como um momento único e estático, que antecedia a implementação prática do mesmo (a esteira fordista é o seu paradigma). O que se detecta como problema é o fato de que, uma vez projetado, o sistema permanecia sem atualização e sem inovação, visto que fora "projetado no início" e se "congelou", no tempo e no espaço. Assim, permanecia sem atualização o projeto implementado, o qual se mantinha, ao longo do tempo, sem alteração, sem inovação e reproduzindo as formas previstas, longo tempo atrás, no seu escopo inicial.

Quando prevalece a concepção tradicional de projeto, anteriormente descrita, ela tende a bloquear a dinâmica de inovação necessária, dada no circuito virtualatual, conforme já discutido pelas Figuras 1 (C-S) e 2 (EpF-P), e conforme demonstrado na Figura 3 abaixo.

No caso desse bloqueio da inovação, o fluxo que vai do virtual ao atual é impedido (sentido descendente da seta, do Plano $A B$ dado pela base do cone invertido, ao Ponto S do presente, localizado no Plano P (atual) da Figura 3). O mesmo ocorre com o sentido ascendente, de $S$ até $A B$, também impedido. Este último refere-se à atividade de reflexão com base na ação, como no conhecimento reflexivo descrito por Peschl (2006). 


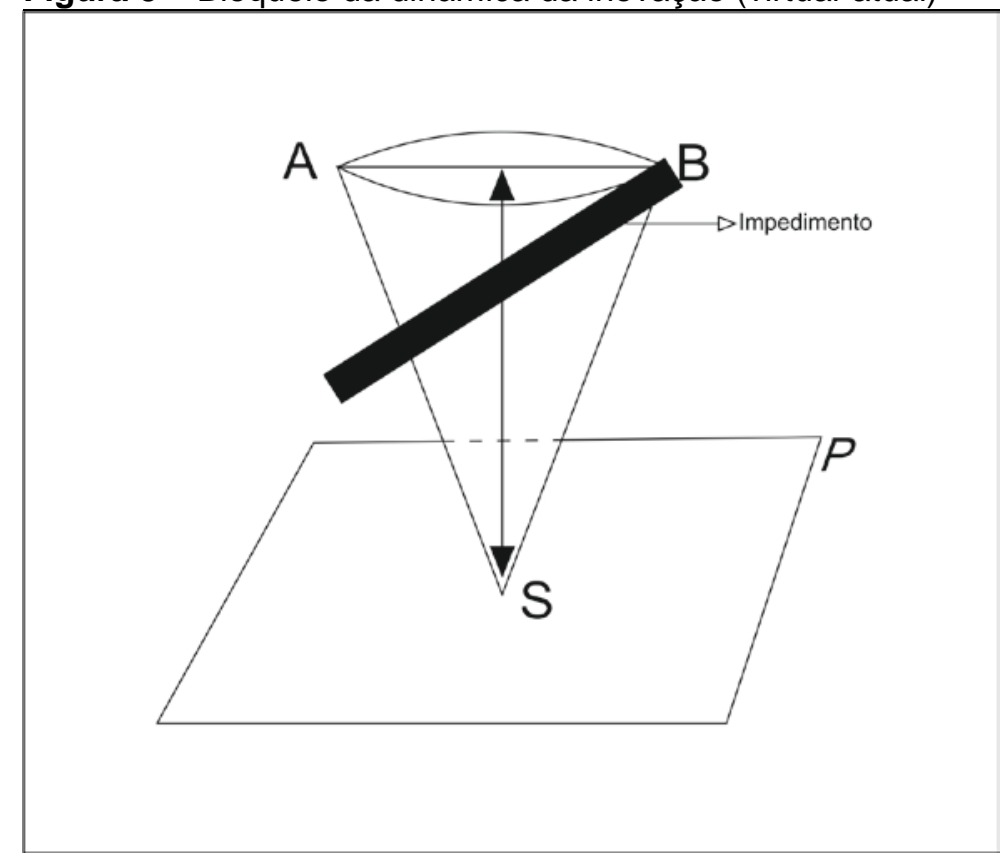

Busca-se, então, uma nova concepção, uma nova noção (ontológica), de projeto, a qual não pode ser separada da noção de inovação. O "projetar" é um processo dinâmico, não estático. Projetar é recriar/inovar, constantemente, de forma contínua, o trabalho, o sistema/processo de trabalho, e as competências envolvidas no trabalho (LE BOTERF, 1998). Não se pode, portanto, estabelecer que o projeto será "refeito" ou que haverá um "reprojeto" de tempos em tempos. Em tempo contínuo, ininterruptamente, é momento de refazer o projeto, de inovar, de permitir um fluxo de criação/inovação, que efetivamente se materialize em transformações concretas do processo de produção. Isso traz para a noção de projeto os termos aqui discutidos:

- Atualização;

- Inovação;

- Memória (do projeto e dos sujeitos);

- Imagem virtual do projeto ou projeto como imagem virtual;

- Imagem atual do projeto;

- Imagem-cristal do projeto (Figura 4).

Se aqui se discute essa nova abordagem de projeto-inovação; tradicionalmente, os processos de projetar geralmente estiveram associados à ideia de imobilização ou fixação do tempo e do espaço, de forma crônica (Ford foi o seu 
representante). O paradigma clássico da ideia de projeto como imobilização e fixação foi a esteira fordista (ZARIFIAN, 1999, em sua noção de co-presença). Fixava-se, pelo projeto da esteira, o tempo e o espaço.

Mas a noção de real do trabalho / facticidade engloba o imprevisto, a variabilidade, a incerteza, as oscilações e turbulências - o não-previsto no projeto: os disfuncionamentos, os incidentes, as panes e desvios inesperados de qualidade. Estas categorias, etiologicamente típicas de um sistema complexo (LEPLAT, 2004), representam aquilo que não se circunscreve ao controle pleno da situação dinâmica, e sim a um controle parcial (HOC, 2004). Segundo a literatura da Ergonomia, são categorias que convidam ao uso da inteligência astuciosa (da prática), da inventividade, do saber-fazer (tácito) e dos compromissos cognitivos dos trabalhadores (AMALBERTI, 1996, 2004), situados também no "fato virtual" do real do trabalho (HUBAULT, 2004, p. 123). Esse conteúdo subjetivo (cognitivo) lança o projeto para a contradição de "projetar" o que não se inseria no projeto tradicional. O trabalho (a ser projetado) é toda esta parcela virtual. O "projetar" da atualidade é um "projetar" inserido na dinâmica virtual-atual, conforme descrito anteriormente.

Isso implica que, no projeto moderno, novas formas de controle devem ser criadas, absolutamente distintas das regras de controle de um sistema previsível e estático. Os novos mecanismos de controle devem incluir, em sua própria concepção, as noções de situação dinâmica (HOC, 2004); complexidade, incerteza e variabilidade (LEPLAT, 2004). Se a esteira fordista era projetada num momento em que se podia controlar o processo/sistema como um sistema estático, linear e causal - hoje, os sistemas de produção e trabalho contemporâneos são pautados pelas características de um sistema turbulento, dinâmico, complexo, com suas características inerentes de incerteza, variabilidade e possibilidades limitadas de controle (HOC, 2004; LEPLAT, 2004; ZARIFIAN, 1999; THEUREAU, 2004; AMALBERTI, 1996, 2004).

$\mathrm{Na}$ atualidade, a imobilização das competências já não permite mais o alcance dos objetivos da produção, como a rentabilidade, a produtividade e o desenvolvimento econômico (ZARIFIAN, 1999; LEPLAT, 2004). O trabalhador é solicitado a aprimorar, em caráter contínuo, suas competências, como pré-requisito 
para lidar com a complexidade e o dinamismo dos novos processos/sistemas de produção (LEPLAT, 2004). Mas ainda que a inovação das competências seja uma premissa, no nível de algo imprescindível para a competitividade, ainda assim, verifica-se que a noção tradicional de projeto não incluía, em seu escopo, algo como um "projeto de desenvolvimento/inovação de competências" (LE BOTERF, 1998) para lidar com a complexidade, no binômio de mútua interação complexidadecompetência, descrito por J. Leplat (LEPLAT, 2004).

\section{A DINÂMICA VIRTUAL $\rightleftarrows$ ATUAL NO PROJETO ERGONÔMICO INOVADOR DO TRABALHO}

Adota-se, neste texto, a metáfora do cristal deleuziano, oriundo do bergsonismo (DELEUZE, 2007, p. 99-104), como imagem de um projeto inovador. O projeto inovador abriga a dinâmica virtual-atual/atual-virtual, descrita por Bergson (1999) e Deleuze (2007, p. 101); no sentido de um potencial criativo, que envolve o ininterrupto processo de geração do novo - a se materializar no Plano P atual, da inovação, precisamente no Ponto S (material), das Figuras 2 e 3. Essa dinâmica da inovação ocorre pela mudança de natureza do virtual ao atual (BERGSON, 1999), verificada na descida ininterrupta do virtual (potencial criativo e inventivo ou Plano $A B$ das Figuras 2 e 3) para o presente material (materialização/atualização do virtual no atual, no Plano $P$, em seu ponto $S$ ).

A fonte da inovação, em um projeto já em funcionamento, vem da criatividade, da inventividade, da iniciativa e, enfim, das competências dos sujeitos inseridos no processo/sistema - o plano virtual AB (Figuras 2 e 3), a se atualizar continuamente no plano presente $\mathrm{P}$. Todo este volume criativo permanece como uma pura virtualidade (BERGSON, 1999), se não for atualizado (objetivado/materializado). Tem-se uma imagem virtual do projeto, mostrada na Figura 4, que permaneceria sem conversão em símbolos e linguagens, caso não houvesse um processo premeditado de explicitação das ideias, lembranças e memória dos sujeitos envolvidos. 
Mobilizar, no sistema de produção, este volume virtual (HUBAULT, 2004, p. 123), na forma de um novo projeto, implica em construir uma imagem que permita condensar a criatividade dos envolvidos. Trata-se de um circuito entre o virtual e o atual. O virtual precisa se atualizar, ou seja, materializar/objetivar-se no presente, numa conversão (mudança de natureza) daquilo que é puramente imagem virtual para uma imagem atual, a ser implementada como estruturas e novas formas de funcionamento do processo/sistema - o circuito virtual-atual reformulado na Figura 4 abaixo.

A imagem atual é o presente. E o seu passado - portador de memória, criatividade, inovação, inventividade e lembranças - é a imagem virtual. Aqui, não significa o passado do projeto, mas o passado tal qual na concepção de Bergson (1999), como um fluxo interminável sobre o presente, e como memória do projeto.

Uma imagem do projeto logo se torna passado (e aqui se tem a essência da dinâmica do projeto inovador...), tão logo novas soluções, criações, ideias, inventividade e criatividade se tornem algo materializado/objetivado - uma imagem do presente ou imagem atual (Figura 4). Assim que se objetivam e se concretizam, elas deixam o seu estado virtual, inserindo-se numa natureza diferente deste, para assumir forma no presente atual, na atualização:

- Implementação de novas tecnologias;

- Novas Técnicas;

- Métodos inovadores.

Imediatamente, um outro virtual vem a se atualizar (se materializar/objetivar) no presente. Quando essa passagem é bloqueada, o projeto perde sua dinâmica de inovação, como mostrado na Figura 3.

Ou como afirma Gilles Deleuze, com base em Bergson (1999), o passado coexiste com o presente, no circuito imagem virtual / imagem atual (DELEUZE, 2007, p. 101) da Figura 4. A imagem atual é o presente e a imagem virtual é o seu passado contemporâneo (tipo uma imagem especular). Um novo presente é o resultado da atualização. Percebe-se disso, aplicando o circuito na dinâmica inovadora, que aquilo que deve se conservar num projeto é a inovação - o ciclo dinâmico virtual-atual. Ou seja, a imagem atual do presente deve passar e a imagem 
virtual do passado deve se conservar. Passado, nesta abordagem, não significa o velho ou o desatualizado, e sim sinônimo de virtual: aquele potencial criativo e inovador (memória, lembrança, subjetividade).

Cabe observar, na Figura 4 que, quando a imagem virtual se cristaliza, no atual, ela se torna uma imagem cristal ou imagem cristalina do projeto, para usar os termos deleuzianos oriundos do bergsonismo (DELEUZE, 2007, p. 99-104; 1966). Isso consiste na égide da implementação do virtual (memória, saberes, lembranças e subjetividade) como produtos da inovação, materializados numa imagem atual. Ou seja, não há atual que não tenha sua origem no virtual (HUBAULT, 2004, p. 123; BERGSON, 1999), nos processos de inovação e projeto.

Figura 4 - O circuito dinâmico da Imagem Cristal (IC) do projeto Inovador

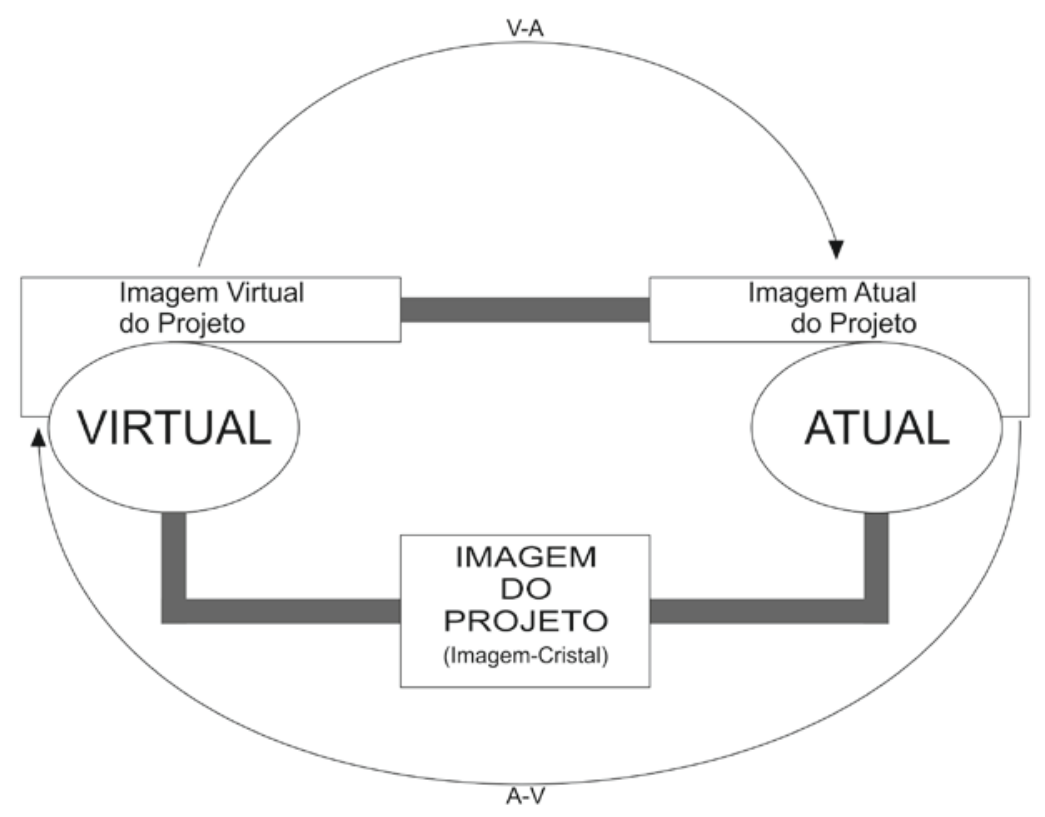

Verifica-se o tempo não-cronológico no cristal-projeto inovador. O circuito da imagem-cristal (Figura 4) permanece em contínuo movimento entre as duas imagens distintas que o constituem: a imagem atual do presente (que passa), e a imagem 
virtual do passado (que se conserva) - distintas e indiscerníveis (DELEUZE, 2007, p. 99-104).

Isso permite notar que o cristal-projeto inovador apresentará diferentes estados, em função dos atos de sua formação e dados nele registrados, contrariando paradoxalmente o modelo tradicional do projeto que congelava 0 passado e o mantinha bloqueado de atualização (faixa preta de "impedimento" no cone invertido da Figura 3). Deleuze (2007, p. 99-104) denomina cada um destes estados de cristal de tempo.

Imagem virtual e imagem atual coexistem e se cristalizam na imagem-cristal da Figura 4, constituindo um circuito dinâmico, que leva constantemente de uma a outra. No caso da nova concepção do projeto, inovador e dinâmico, este cristalizarse implica em inovar pela experiência do passado subjetivo (ideias, saberes, experiências, criatividade, lembranças). Ao invés de permanecer sempre objetivado como um modelo anacrônico (concepção tradicional de projeto), um projeto inovador deve, em caráter contínuo e ininterrupto, conduzir do subjetivo ao objetivo, do virtual ao atual, permitindo que o fluxo de criação e de saberes dos agentes envolvidos venha a se materializar no presente.

\section{CONSIDERAÇÕES FINAIS}

A contribuição deste trabalho vai no sentido de incrementar a inovação via um sistema diferenciado de elaboração e desenvolvimento do projeto inovador. Por exemplo, inovação e projeto andam juntos, na perspectiva oferecida aos leitores, demandando a dinâmica entre o atual e o virtual. Os resultados impactam fortemente a potencialidade da organização, numa mudança cultural alinhada com tudo o que foi exposto neste artigo. Nova mentalidade, nova organização: novo desempenho e nova eficiência. Isso pode dinamizar a qualidade do produto e desenvolver, intrinsecamente, os modelos de produção. Estar sempre migrando para o virtual e, em seguida, para o atual, implica numa maturação constante, e na competitividade de alto nível, do produto e do processo.

Revista Produção Online, Florianópolis, SC, v.15, n. 4, p. 1273-1304, out./dez. 2015. 
Pode-se concluir, pela contribuição teórico-conceitual anteriormente proposta, que no projeto ergonômico inovador do trabalho, deve haver uma coexistência da imagem atual do projeto e a imagem virtual do projeto. O processo que leva de uma à outra é dinâmico, durável continuamente no tempo, e inovador. Como dito, elas, em conjunto, integram a IC - e se situam num circuito que leva de uma a outra, constituindo essa Imagem Cristal da inovação (Figura 4). Muito se fala de inovação nos dias de hoje, e também em gestão estratégica. Buscamos demonstrar aqui que estes processos dependem de uma busca constante (um salto constante) rumo ao virtual enquanto manancial da criatividade, das mentalidades inovadoras e criativas, as quais mobilizam a empresa líder.

Uma contribuição possível para que parte do real do trabalho se torne "projetável", numa nova concepção dinâmica, integradora e mais completa que a anterior, do projeto tradicional. Os estados do projeto, movimentados em fluxo contínuo na dinâmica do circuito da Figura 4, sintetizam a presente proposta. Os processos ultrapassados do projeto tradicional, nos aspectos de desenvolvimento de produto e ergonomia, tendem a desaparecer ante o projeto inovador, embora, em alguns setores mais precários, Taylor permaneça vivo na produção.

Propôs-se, aqui, que o projeto inovador do trabalho consiste, justamente, em partir para a busca da compreensão deste virtual - o real do trabalho e sua concretude, o trabalho real - em prol de uma concepção de tarefas que se aproximem do próprio real, e reduzam as dificuldades - a facticidade - com as quais os trabalhadores têm de lidar na atividade de trabalho. Este ponto de vista ergonômico tende a permitir um movimento rumo à produtividade em conjunto com a qualidade de vida no trabalho.

Como sugestão para trabalhos futuros, aponta-se a possibilidade, talvez cientificamente promissora, de validar empiricamente as teorias e conceitos aqui propostos (nesta sintética contribuição teórico-conceitual), em sistemas/processos/projetos de serviços e nas situações dinâmicas (HOC, 2004) dos processos de produção do setor industrial. Provavelmente, com a consolidação empírica do presente programa de pesquisa, novos campos de pesquisa talvez se mostrarão de interesse para as áreas de engenharia de produção, conhecimento \& 
inovação, gestão do conhecimento, organização do trabalho, ergonomia e segurança do trabalho.

\section{REFERÊNCIAS}

ABRAHÃO, J.I. Reestruturação produtiva e variabilidade do trabalho: uma abordagem da ergonomia. Psicologia: Teoria e Pesquisa, v. 16, n. 1, p. 49-54, 2000.

http://dx.doi.org/10.1590/S0102-37722000000100007

ABRAHÃO, J.I.; TORRES, C.C. Entre a organização do trabalho e o sofrimento: o papel de mediação da atividade. Produção, v.14, n.3, p. 67-76, 2004.

http://dx.doi.org/10.1590/S0103-65132004000300008

AMALBERTI, R. De la gestion des erreurs à la gestion des risques. In: FALZON, P. Ergonomie. Paris, PUF, p. 285-300, 2004. http://dx.doi.org/10.3917/puf.falzo.2004.01.0285

AMALBERTI, R. La conduite de systèmes à risques. Paris: PUF, 1996.

ARENDT, R.J.J. O desenvolvimento cognitivo do ponto de vista da enação. Psicologia:

Reflexão e Crítica, v.13, n.2, p. 223-231, 2000.

http://dx.doi.org/10.1590/S0102-79722000000200003

BATIONO-TILLON, A.; FOLCHER, V.; RABARDEL, P. Les artefacts transitionnels: une proposition pour étudier la diachronie des activités narratives. Activités, v.7, n.2, pp. 63-83, 2010.

BERGSON, H. Essai sur les données immédiates de la conscience. Paris: Presses Universitaires de France, 2007.

BERGSON, H. La pensée et le mouvant. Paris: Presses Universitaires de France, 2004.

BERGSON, H. Matière et mémoire. Paris: Presses Universitaires de France, 1999.

BRAVERMAN, H. Labor and monopoly capital: the degradation of work in the twentieth century. New York: Monthly Review Press, 1974.

CHALMERS, A. F. What is this thing called science? Indianapolis: Hackett Publishing, 1999.

CLOT, Y. La fonction psychologique du travail. 4. ed. Paris: PUF, 2004.

CUNHA, V.P.; OLIVEIRA, M.G.; ROZENFELD, H. Planejamento da inovação: análise e identificação das suas principais fases. Revista Produção Online, v.13, n. 2, 2013.

CURIE, J. Condições da pesquisa científica em ergonomia. In: DANIELLOU, F. (Coord.). A ergonomia em busca de seus princípios: debates epistemológicos. São Paulo: Edgard Blücher, p. 19-28, 2004. 
DANIELLOU, F. Questões epistemológicas levantadas pela ergonomia de projeto. In: DANIELLOU, F. (Coord.). A ergonomia em busca de seus princípios: debates epistemológicos. São Paulo: Edgard Blücher, p. 181-198, 2004.

DANIELLOU, F. \& BÉGUIN, P. Méthodologie de l'action ergonomique: approches du travail réel. In: FALZON, P. (Org.). Ergonomie. Paris, PUF, 2004, p. 335-358.

http://dx.doi.org/10.3917/puf.falzo.2004.01.0333

DELEUZE, G. Os cristais de tempo. In: DELEUZE, G. A imagem-tempo. São Paulo: Brasiliense, 2007, pp. 87-120.

DELEUZE, G. Le bergsonisme. Paris: PUF, 1966.

DINIZ, E. P. H.; ASSUNÇÃO, A. A.; LIMA, F. P. A. Prevenção de acidentes: o reconhecimento das estratégias operatórias dos motociclistas profissionais como base para a negociação de acordo coletivo. Ciência \& Saúde Coletiva, v. 10, n.4, p. 905-916, 2005. http://dx.doi.org/10.1590/S1413-81232005000400014

ESPINOLA, M.J.C; VILAR, R.M; BARROS, M.A; SILVA, L.B; Um indicador do potencial de retorno de investimentos em inovação voltado para regiões do território brasileiro; Revista Produção Online, v.9, n. 2, p. 624-649, set. 2009. Disponível em http://www.producaoonline.org.br/index.php/rpo/article/view/189/499. http://dx.doi.org/10.14488/1676-1901.v9i3.189

FRAZZON, L.S.; INOMATA, D.O.; OLIVEIRA, K.F.; FORCELLINI, F.A. O processo de desenvolvimento de um serviço inovador com base em um modelo de referência. Revista Produção Online, v.15, n.2, 2015.http://dx.doi.org/10.14488/1676-1901.v15i2.1933

FREYSSENET, M. La division capitaliste du travail. Paris: Savelli, 1977.

GORZ, A. Métamorphoses du travail: critique de la raison économique. Paris: Galilée, 1988.

GUÉRIN, F; LAVILLE, F; DANIELLOU, F; DURAFFOURG, J; KERGUELEN, A.

Compreender o trabalho para transformá-lo: a prática da ergonomia. São Paulo: Edgard Blücher, 2001.

HOC, J.M. Vers une coopération homme-machine en situation dynamique. In: FALZON, P. Ergonomie. Paris, PUF , 2004, p. 269-283. http://dx.doi.org/10.3917/puf.falzo.2004.01.0269

HUBAULT, F. Do que a ergonomia pode fazer a análise? In: DANIELLOU, F. (Coord.). A ergonomia em busca de seus princípios: debates epistemológicos. São Paulo: Edgard Blücher, 2004, pp. 105-140.

LAZZARI, F.; BAMPI, R.E.; MILAN, G.S. Os esforços de inovação e sua relação com alguns indicadores de desempenho do negócio. Revista Produção Online, v.14, n.1, 2014. http://dx.doi.org/10.14488/1676-1901.v14.i1.1428

LE BOTERF, G. L'ingénierie des compétences. Paris: Éditions d'Organisation, 1998.

LEPLAT, J. Reperes pour l'analyse de l'activite en ergonomie. Paris: PUF, 2008. 
LEPLAT, J. Aspectos da complexidade em ergonomia. In: DANIELLOU, F. (Coord.). A ergonomia em busca de seus princípios: debates epistemológicos. São Paulo: Edgard Blücher, p. 57-77, 2004.

LINHART, D. Subjectivité collective et travail. In: CLOT, Y.; LHUILIER, D. (Eds.). Travail et santé: ouvertures cliniques. Paris: Érès, p. 65-77, 2010.

LORINO, P. Concevoir l'activité collective conjointe : l'enquête dialogique. Étude de cas sur la sécurité dans l'industrie du bâtiment. Activités, v. 6, n. 1, p. 87-110, 2009.

LOURDES, C.; FIGUEIREDO, P.N. Mensuração de capacidades tecnológicas inovadoras em empresas de economias emergentes: méritos limitações e complementaridades de abordagens existentes. Revista Produção Online, v.9, n.1, p. 95-12, mar. 2009. Disponível em: <http://www.producaoonline.org.br/index.php/rpo/article/viewFile/213/314>. http://dx.doi.org/10.14488/1676-1901.v9i1.213

PASTRÉ, P. Genèse et identité. In: RABARDEL, P.; PASTRÉ, P. (Orgs.). Modèles du sujet pour la conception: dialectiques activités développement. Paris: Octarès, p. 231-260, 2005.

PEIXOTO, L.S.R; ALMEIDA, M.P; VIANA, J.C.F; Sistema setorial de inovação na indústria química de Alagoas; Revista Produção Online, v.9, n. 2, p. 600-623, set. 2009. Disponível em http://www.producaoonline.org.br/index.php/rpo/article/view/209/511 http://dx.doi.org/10.14488/1676-1901.v9i3.209

PESCHL, M.F. Modes of knowing and modes of coming to know: knowledge creation and co-construction as socio-epistemological engineering in educational processes.

Constructivist Foundations, v.1, n.3, p. 111-123, 2006.

PIZO, C. A.; MENEGON, N. L. Análise ergonômica do trabalho e o reconhecimento científico do conhecimento gerado. Produção, v. 20, n. 4, p. 657-668, 2010. http://dx.doi.org/10.1590/S0103-65132010005000058

SCHON, D. A. Educando o profissional reflexivo: um novo design para o ensino e a aprendizagem. Porto Alegre: Artes Médicas, 2000.

SCHWARTZ, Y. Trabalho e valor. Tempo Social: revista social USP, v. 8, n. 2, p. 147-158, 1996.

SILVA, F.G.; HARTMAN, A.; REIS, D.R. Avaliação do nível de inovação tecnológica nas organizações: desenvolvimento e teste de uma metodologia. Revista Produção Online, v.8 n.4, dez. 2008 Disponível em:

<http://producaoonline.org.br/index.php/rpo/article/viewFile/139/221>. http://dx.doi.org/10.14488/1676-1901.v8i4.139

THEUREAU, J. Cours d'action : méthode élémentaire. Toulouse: Octarès, 2004.

VARELA, F. J. The specious present: a neurophenomenology of time consciousness. In: Naturalizing phenomenology: issues in contemporary phenomenology and cognitive science. Stanford: Stanford University Press, p. 266-314,1999. 
VASCONCELOS, R.C.; LIMA, F.P.A.; CAMAROTTO, J.A.; ABREU, A.C.M.S.; COUTINHOFILHO, A.O.S. Aspectos de complexidade do trabalho de coletores de lixo domiciliar: a gestão da variabilidade do trabalho na rua. Gestão \& Produção, v. 15, n. 2, p. 407-419, 2008. http://dx.doi.org/10.1590/S0104-530X2008000200015

VYGOTSKY, L. S. Teoria e método em psicologia. São Paulo: Martins Fontes, 1996.

WHITE, K. Razão, justiça e modernidade: a obra recente de Jürgen Habermas. São Paulo: Ícone, 1995.

WISNER, A. Questões epistemológicas em ergonomia e em análise do trabalho. In: DANIELLOU, F. (Coord.). A Ergonomia em busca de seus princípios: debates epistemológicos. São Paulo: Edgard Blucher, p. 29-55, 2004.

WISNER, A. Organização do trabalho, carga mental e sofrimento psíquico. In: WISNER, A. A inteligência no trabalho: textos selecionados de ergonomia. São Paulo: FUNDACENTRO, p. 11-20,1994.

WISNER, A. Por dentro do trabalho: ergonomia: método \& técnica. São Paulo: FTD Oboré, 1987.

ZARIFIAN, P. Objectiv Compétence. Paris: Liasons, 1999.

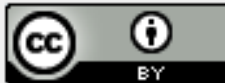

Artigo recebido em 17/07/2014 e aceito para publicação em 13/10/2015

DOI: http://dx.doi.org/ 10.14488/1676-1901.v15i4.1827 